\title{
Erratum to: Phylogenetic Analyses on the Diversity of Aspergillus fumigatus Sensu Lato Based on Five Orthologous Loci
}

\author{
Fang Li $\cdot$ Bo Wang $\cdot$ Long Wang $\cdot$ Bin Cao
}

Published online: 1 November 2014

(C) Springer Science+Business Media Dordrecht 2014

Erratum to: Mycopathologia (2014) 178:163-176

DOI 10.1007/s11046-014-9790-0

In the second sentence of the section, Results/ Recognized STs and Population Structure the GenBank Accession Number KJ83165 should be KJ831653.

The online version of the original article can be found under doi:10.1007/s11046-014-9790-0.

F. Li · B. Cao $(\bowtie)$

Department of Infectious Diseases and Clinical

Microbiology, Beijing Chao-Yang Hospital, Capital

Medical University, Beijing 100020, China

e-mail: caobin1999@gmail.com

B. Wang

College of Forestry, Northwest A\&F University,

Yangling 712100, Shaanxi, China

L. Wang $(\bowtie)$

State Key Laboratory of Mycology, Institute of

Microbiology, Chinese Academy of Sciences,

Beijing 100101, China

e-mail:wl_dgk@sina.com; wl_dgk@yahoo.com.cn;

wl_dgk@hotmail.com 